\title{
Relationship Between Concept Recognition of a Product/Service Brand and Willingness to Pay
}

\author{
Takumi KATO* \\ * Saitama University, 255 Shimo-Okubo, Sakura-ku, Saitama City, Saitama 338-8570, Japan \\ takumikato@mail.saitama-u.ac.jp
}

\begin{abstract}
Consumers who value superficial performance and design are more likely to change their minds when a brand with higher performance or a more fashionable design emerges. On the other hand, loyal consumers understand, sympathize with, and value brand concept. Therefore, their repurchase rate is high and they are willing to pay a higher amount than for similar products from other companies. However, in marketing practice and research, there is little awareness of evaluating whether or not the brand concept is being communicated to consumers. Therefore, in this study, the relationship between concept recognition and willingness to pay was clarified. Consequently, the study confirmed that there is a significant difference in the willingness to pay in consumers who recognize the brand concept. This result provides a suggestion to reaffirm the significance of the concept so as not to waste excellent means and technologies.
\end{abstract}

Keywords: Brand Concept, Loyalty, Emotional Value, Functional Value, Consistent Embodiment

\section{INTRODUCTION}

Functional differentiation has become difficult, and the influence of emotional value has further increased. In order to foster emotional value, it is necessary to define a concept that solves the practical and psychological problems of consumers, and to examine design and UX (User eXprience) consistency based on it. The importance of emotional value is widely recognized and concrete activities such as the recruitment of chief design officers and the introduction of design thinking are evidence of this. However, there are few examples of where a strong brand has been established through these activities. The root cause is that concepts are often ambiguous. The purpose of this study is to utilize design and UX as a means into this end. Consumers who value superficial performance and design are more likely to change their minds when a brand with higher performance or a more fashionable design emerges. On the other hand, loyal consumers understand, sympathize with, and value the brand concept. That is why the repurchase rates and willingness to pay of some brands remain high $[1,2]$.

Until now, brand concept has rarely been used to evaluate brand loyalty in industry and academia. This study aims to clarify the relationship between concept recognition and willingness to pay and to provide suggestions to reaffirm the significance of the concept so as not to waste excellent means and technologies.

\section{IDEAS ORIGIN AND CRITERIA BY CONCEPTS}

The concept is the value definition of goods and services. As the framework, target (Who), value and positioning (What), and execution method (How) are known $[3,4]$. Concepts serve as the starting point for ideas and the criteria for decision-making. When the concept is ambiguous, the idea for embodying it is often forgotten, and the purpose is often changed in the pursuit of performance and multi-functionality. However, they do not contribute to consumer purchasing behavior [5]. Without decision-making criteria, subjective design and UX are more influenced by evaluator preferences and less consistent.

Therefore, in order for a product/service to succeed as a strong brand, it is necessary to define the concept clearly before entering the market and to maintain it consistently in the perception of consumers, even after the start of sales [6]. The range covers various touch points such as websites and retail stores [7]. It is also important that the technology associated with the brand name [8], which has more influence than the technology itself, also matches the concept. As a result, it helps consumers to distinguish one brand from other brand products and services [9].

Although the importance of concepts has been known for a long time, the evaluation of the influence of consumers' concept recognition has been inadequate. 


\section{SURVEY AND EVALUATION METHOD}

The purpose of this study is to clarify the relationship between concept recognition and willingness to pay, to verify whether there is a significant difference in the willingness to pay between consumers who recognize the concept (treatment group) and consumers who do not (control group). If the two groups are simply compared, the pure impact of concept recognition cannot be evaluated because brand loyalties may differ. Therefore, by propensity score matching, both groups were corrected to the same group except for concept recognition.

The target brands were Apple MacBook Pro, Dyson Canister Vacuum Cleaner, and Nintendo Switch as products, and Facebook, Starbucks, and Disney as services. The reason for targeting these brands is that their concepts are clear. The concepts for each brand are as follows: Apple MacBook Pro: "The ultimate work tool for professionals who innovate in the world"[10]; Dyson Canister Vacuum Cleaner: "The cleaner that doesn't lose suction" [11]; Nintendo Switch: "Transforming from home console to portable system in a snap" and "Controllers give you total gameplay flexibility" [12]; Facebook: "Give people the power to build a community and bring the world closer together" [13]; Starbucks: "Third place" [14]; and Disney (Tokyo Disney Resort): "The kingdom of dreams and magic"[15].

An online survey was conducted in Japan in November 2020. Respondents' conditions were set as follows: (a) $20 \mathrm{~s}$ to $50 \mathrm{~s}$, (b) purchase new products from three product brands, (c) use the target brand at least once a month (in the case of Disney at least once every 2-3 years). The sample size was 400 for each brand, for a total of 2,400.

The survey consisted of a screening survey and a main survey. The purpose of the screening survey was to select respondents who met conditions (a)-(c). The items included were: gender, age, area of residence, occupation, annual household income, ownership and purchase method for each product brand, and frequency of use of each product/service brand. The respondents who met the conditions were included in the main survey. If multiple brands met the conditions, participants were randomly assigned to a brand. The following items were scored for each target brand: satisfaction, recommendation intention, willingness to pay, and concept recognition. The loyalty index (satisfaction and recommendation intention) was based on a 7-point scale (1: very unsatisfied; 4: I do not know; 7: very happy). For willingness to pay, the question was, "If you were to buy the target product again, would you be willing to pay a higher price than for other brands?" As shown in Table 1, Apple had the highest ranking for willingness to pay and Facebook the lowest. Since Facebook is free, there is a high psychological barrier to paying. In the question for concept recognition, in addition to the concept of each brand already shown, 6 dummy concepts and "Don't know" were presented as options. For Disney, the dummy concepts were: "Providing the best service in the world," "The customer is God," and "Value optimized for each person." As shown in Table 2, Disney has the highest recognition rate and Facebook has the lowest recognition rate.

Table 3 shows that the mean for loyalty were higher in the recognition group. The propensity score was estimated by a logistic regression model in which recognition/non-recognition was used as the objective variable and items $1-32$ of Table 3 as the explanatory variables. The stepwise method was applied to the model building. Using the estimated propensity score, matching was performed so that the scores were homogeneous in both groups. Finally, the chi-square test examined the differences in willingness to pay between the two groups. The analysis environment was R.

\section{RESULTS AND DISCUSSION}

Table 4 shows the results of a logistic regression model for estimating propensity scores. Based on the characteristics of consumers who recognize a brand, Dyson, Nintendo, and Disney had the highest scores for frequency of use and recommendation intention. The c-statistics value was 0.689 , which is generally a good value. As a result of propensity score matching, 323 people from each group were extracted. Table 3 shows that both groups were homogenized after matching. For Disney it was (Unrecognized: 0.134, Recognized: 0.378) to $(0.381,0.378)$, respectively, and Recommendation from $(5.128,5.508)$ to $(5.523,5.508)$, respectively.

Table 5 shows the matrix for concept recognition and willingness to pay. As a result of the chi-square test, $\mathrm{p}=0.021$ and the null hypothesis "there is no difference in willingness to pay depending on the presence or absence of concept recognition" were rejected at the 5\% significance level. In other words, consumers who recognize a concept tend to have a higher willingness to pay. The odds ratio was 1.460 .

The study has two limitations. First, there is a limit to generalization as only six brands were included. Second, the results may vary depending on the setting of the concept recognition dummy options. The ideal is to listen with pure recall, which does not present options. 
Table 1: Willingness to pay higher than other companies in each brand

\begin{tabular}{crrrrrrr}
\hline Willingness to pay & \multicolumn{1}{c}{ Apple } & \multicolumn{1}{c}{ Dyson } & Nintendo & Facebook & Starbucks & Disney & \multicolumn{1}{l}{ Total } \\
\hline No & 90 & 153 & 249 & 333 & 125 & 164 & 1,114 \\
Yes & 310 & 247 & 151 & 67 & 275 & 236 & 1,286 \\
\hline Total & 400 & 400 & 400 & 400 & 400 & 400 & 2,400 \\
\hline
\end{tabular}

Table 2: Concept recognition in each brand

\begin{tabular}{lrrrrrrrr}
\hline \multicolumn{1}{c}{ Concept } & \multicolumn{1}{c}{ Apple } & Dyson & Nintendo & Facebook & Starbucks & Disney & Total & Group \\
\hline Don't know & 302 & 304 & 320 & 327 & 318 & 244 & 1,815 & Unrecognized \\
Incorrect answer & 69 & 40 & 25 & 45 & 49 & 34 & 262 & \\
Correct answer & 29 & 56 & 55 & 28 & 33 & 122 & 323 & Recognized \\
\hline Total & 400 & 400 & 400 & 400 & 400 & 400 & 2,400 & - \\
Correct ratio & $7.3 \%$ & $14.0 \%$ & $13.8 \%$ & $7.0 \%$ & $8.3 \%$ & $30.5 \%$ & $13.5 \%$ & - \\
\hline
\end{tabular}

Table 3: Mean of respondent attributes and loyalty indicators before and after propensity score matching

\begin{tabular}{|c|c|c|c|c|c|c|}
\hline \multirow{2}{*}{ No } & \multirow{2}{*}{ Variable } & \multirow{2}{*}{ Description } & \multicolumn{2}{|c|}{ Before Matching } & \multicolumn{2}{|c|}{ After Matching } \\
\hline & & & Unrecognized & Recognized & Unrecognized & Recognized \\
\hline 1 & Apple & Target brand dummy & 0.179 & 0.090 & 0.121 & 0.090 \\
\hline 2 & Dyson & (Criteria: Facebook) & 0.166 & 0.173 & 0.170 & 0.173 \\
\hline 3 & Nintendo & & 0.166 & 0.170 & 0.164 & 0.170 \\
\hline 4 & Starbucks & & 0.177 & 0.102 & 0.093 & 0.102 \\
\hline 5 & Disney & & 0.134 & 0.378 & 0.381 & 0.378 \\
\hline 6 & Female & Gender dummy & 0.490 & 0.483 & 0.508 & 0.483 \\
\hline 7 & Age_20s & Age dummy & 0.257 & 0.272 & 0.294 & 0.272 \\
\hline 8 & Age_30s & (Criteria: Age_50s) & 0.261 & 0.263 & 0.276 & 0.263 \\
\hline 9 & Age_40s & & 0.247 & 0.241 & 0.229 & 0.241 \\
\hline 10 & Area_02_Tohoku & Residential area dummy & 0.050 & 0.043 & 0.046 & 0.043 \\
\hline 11 & Area_03_Hokuriku & (Criteria: Area_01Hokkaido) & 0.055 & 0.043 & 0.084 & 0.043 \\
\hline 12 & Area_04_Kanto & & 0.480 & 0.570 & 0.563 & 0.570 \\
\hline 13 & Area_05_Tokai & & 0.090 & 0.093 & 0.087 & 0.093 \\
\hline 14 & Area_06_Kinki & & 0.156 & 0.118 & 0.096 & 0.118 \\
\hline 15 & Area_07_Chugoku & & 0.061 & 0.046 & 0.043 & 0.046 \\
\hline 16 & Area_08_Kyusyu & & 0.060 & 0.053 & 0.040 & 0.053 \\
\hline 17 & Job_01_Management & Job dummy & 0.037 & 0.028 & 0.034 & 0.028 \\
\hline 18 & Job_02_SalesMarketing & (Criteria: Job_10_Others) & 0.114 & 0.127 & 0.124 & 0.127 \\
\hline 19 & Job_03_Engineer & & 0.125 & 0.121 & 0.108 & 0.121 \\
\hline 20 & Job_04_BackOffice & & 0.113 & 0.127 & 0.124 & 0.127 \\
\hline 21 & Job_05_Profession & & 0.065 & 0.031 & 0.056 & 0.031 \\
\hline 22 & Job_06_Freelance & & 0.042 & 0.043 & 0.046 & 0.043 \\
\hline 23 & Job_07_Parttimer & & 0.133 & 0.118 & 0.155 & 0.118 \\
\hline 24 & Job_08_Homemaker & & 0.139 & 0.170 & 0.142 & 0.170 \\
\hline 25 & Job_09_Student & & 0.040 & 0.053 & 0.034 & 0.053 \\
\hline 26 & Income_600 & Household income dummy & 0.252 & 0.232 & 0.282 & 0.232 \\
\hline 27 & Income_800 & (Criteria: Income_400) & 0.215 & 0.192 & 0.220 & 0.192 \\
\hline 28 & Income_1000 & & 0.135 & 0.161 & 0.118 & 0.161 \\
\hline 29 & Income_1500 & & 0.191 & 0.214 & 0.164 & 0.214 \\
\hline 30 & Frequency & High frequency use dummy & 0.505 & 0.406 & 0.406 & 0.406 \\
\hline 31 & Satisfaction & Loyalty & 5.252 & 5.548 & 5.557 & 5.548 \\
\hline 32 & Recommendation & & 5.128 & 5.508 & 5.523 & 5.508 \\
\hline
\end{tabular}




\section{CONCLUSION}

This study evaluated the relationship between concept recognition and willingness to pay, which has not been clarified so far. The result showed that there was a significant difference in the willingness to pay in consumers who recognize the concept.

One implication for brand management is that the index for concept recognition or concept recall, when asked about the attractiveness of product/service brand, should be emphasized. In general, after measuring loyalty (e.g., recommendation intention and repurchase intention), each specific feature of the product/service should be evaluated and the factors that contribute to loyalty understood. Consumers who value superficial features will change their minds when a better brand emerges; in contrast, consumers who understand, sympathize with, and value the brand's concept have a stronger sense of loyalty.

Design and UX are just the means to embody the concept. The concept should be the criteria for decision-making so as not to turn a means into an end. It is hoped that the index of concept recognition will spread to both the industrial world but also to the academic world that studies consumer behavior and brand management.

Table 4: Result of logistic regression model for estimating propensity score

\begin{tabular}{lrrrl}
\hline & Estimate & Odds ratio & \multicolumn{1}{l}{ SE } & p-value \\
\hline Intercept) & -3.559 & 0.028 & 0.310 & $0.000 * * *$ \\
Dyson & 0.768 & 2.155 & 0.183 & $0.000 * * *$ \\
Nintendo & 0.638 & 1.893 & 0.184 & $0.001 * *$ \\
Disney & 1.646 & 5.187 & 0.178 & $0.000 * * *$ \\
Area_04_Kanto & 0.207 & 1.230 & 0.127 & 0.104 \\
Frequency & 0.140 & 1.151 & 0.148 & 0.341 \\
Recommendation & 0.165 & 1.180 & 0.051 & $0.001 * *$ \\
\hline c-statistics & $0.689(95 \% \mathrm{CI}: 0.657-0.721)$ \\
\hline Note: ${ }^{*} * * \mathrm{p}<0.001 ; * * \mathrm{p}<0.01 ;{ }^{*} \mathrm{p}<0.05$. & &
\end{tabular}

Table 5: Result of chi-square test

\begin{tabular}{lrr|rrr}
\hline \multicolumn{1}{c}{ Concept } & \multicolumn{2}{c|}{ Willingness to pay } & Total & p-value & $\begin{array}{c}\text { Odds } \\
\text { ratio }\end{array}$ \\
\hline No & \multicolumn{1}{c|}{ Yes } & & & \\
\hline Unrecognized & 156 & 167 & 323 & 0.021 & 1.460 \\
Recognized & 126 & 197 & 323 & & \\
\hline
\end{tabular}

\section{ACKNOWLEDGMENTS}

This work was supported by JSPS KAKENHI Grant Number JP20K22115.

\section{REFFERENCES}

[1] Arjun Chaudhuri and Morris B Holbrook; The chain of effects from brand trust and brand affect to brand performance: the role of brand loyalty, Journal of Marketing, 65(2), pp.81-93, 2001.

[2] Darrell K Rigby, Frederick F Reichheld, and Phil Schefter; Avoid the four perils of CRM. Harvard Business Review, 80(2), pp.101-109, 2002.

[3] James R Stengel, Andrea L Dixon, and Chris T Allen; Listening begins at home. Harvard Business Review, 81(11), pp.106-14, 2003.

[4] Alan G Lafley and Roger L Martin; Playing to win: How strategy really works, Harvard Business Press, 2013.

[5] Takumi Kato and Kazuhiko Tsuda; The effect of the number of additional options for vehicles on consumers' willingness to pay. Procedia Computer Science, 176, pp.1540-1547, 2020.

[6] Burleigh B Gardner and Sidney J Levy; The product and the brand. Harvard Business Review, 33(2), pp.33-39, 1955.

[7] Jim Lecinski; Winning the zero moment of truth. Think with Google, 2011, https://www.thinkwithgoogle.com/future-of-marketin g/emerging-technology/2011-winning-zmot-ebook/ (last accessed December 20, 2020).

[8] Takumi Kato; Comparison of the Influence of Self-Driving Technology Brand Name on Purchase Intention Between Japan and the US. Procedia Manufacturing, 39, pp.1369-1376, 2019.

[9] Bobby J Calder; Designing Brands. Kellogg on Branding: The Marketing Faculty of The Kellogg School of Management. John Wiley \& Sons, 2005.

[10] Apple; MacBook Pro, Apple, https://www.apple.com/jp/macbook-pro-16/ (last accessed December 20, 2020)

[11] James Dyson; Against the Odds: An Autobiography, 2, Texere, 2000.

[12] Nintendo; Nintendo Switch, https://www.nintendo.com/switch/system/ (last accessed December 20, 2020)

[13] Facebook; Our Mission. Facebook, https://about.fb.com/company-info/ (last accessed December 20, 2020)

[14] Howard Schultz and Dori J Yang; Pour your heart into it: How Starbucks built a company one cup at a time. Hyperion, 1997.

[15] OLC; Facility overview - Tokyo Disneyland. OLC Group, http://www.olc.co.jp/en/tdr/profile.html (last accessed December 20, 2020) 